\title{
Risk management in blood bank processes: quality applied in prevention of events
}

\begin{abstract}
The risk management should be included in the planning to implement a quality management system in blood banks, given that it makes it possible to identify, characterize, and quantify the potential problems associated with the processes developed to classify them afterwards according to their importance and to elaborate an action plan for each of them. The aim of this work was to weight the use of this tool in process planning managements, being able to extend its use from the blood bank to the remainder of the area of expertise. A matrix of Failure Mode and Effects Analysis (FMEA) was produced from the impact or severity of the failure, the probability of occurrence, and the detection capacity. ${ }^{1}$ The information obtained from the analysis allowed the calculation of the Risk Priority Number (RPN) whose value indicates if the process is under control or if some measures must be incorporated to keep the process under control. The results obtained have demonstrated that knowing the Risk Priority Number of each activity in a planning stage favours the design of a preventive and corrective action plan in advance.
\end{abstract}

Keywords: risk management, risk priority number, action plan, potential risk, FMEA
Volume 5 Issue 3 - 2017

\author{
Alcorta N, Enrique $P$ \\ Cátedra de Calidad en Hemoterapia, Universidad de \\ Concepción del Uruguay Centro Regional Rosario,Argentina
}

\begin{abstract}
Correspondence: Alcorta N, Cátedra de Calidad en Hemoterapia, Universidad de Concepción del Uruguay Centro Regional Rosario, Rosario Provincia de Santa Fe,Argentina,
\end{abstract} Email natyalcorta@hotmail.com

Received: June 05, 2017 | Published: October 12, 2017

\section{Introduction}

When reporting on the state of the $\operatorname{art}^{2}$ it can be noticed that the word risk in the bibliography referring to transfusion medicine only is associated with facilities, work environment, biosafety and catastrophe management. ${ }^{3}$ The technical manual of the American Association of Blood Banks ${ }^{3}$ mentions that "A quality management system includes the organizational structure, responsibilities, policies, processes, procedures and resources established by executive management to achieve and maintain quality". In this respect, the Royal Spanish Academy defines risk as the contingency or proximity of an injury and associates it with different situations or areas assigning a different meaning according to the concept used. For example "Operational risk: risk that a company suffers from the possibility of failures in its own operation". ${ }^{4}$

ISO 31000: $2009^{5}$ mentions that risk is "an effect of uncertainty on the achievement of goals." It is therefore convenient to point out that when mentioning the risk in processes in this article allusions are made to all those situations, behaviours, activities or contingencies that by their nature may cause a process to fail to meet the objective for which it was designed and implemented, or partially do so. That is, in a blood bank can be found risks of not complying with current legislation, not meeting established quality requirements, health risks of staff, etc.

ISO 9001: $2015^{6}$ in chapter 6 refers to planning that a quality management system must address risks and opportunities to prevent or reduce undesirable effects. It also refers to the fact that actions planned to address such risks must be proportional to the potential impact. The purpose of making an AMFE is to identify the causes attributable to each risk to reduce or eliminate them and ensure the quality of the final product of each process. ${ }^{1}$ According to the IPR obtained in each case the actions can cover a range of opportunities, from the implementation of a second operator that controls the process to the reengineering of the same. Identifying potential risks allows designing action plans that require immediate implementation measures, in the short or medium term; ie the head of the blood bank as well as the quality manager from the use of this tool, can know the critical and non-critical points of their processes and can allocate resources early to prevent unwanted effects. The general objective is: To know the potential risks associated with blood bank processes for the design of a control plan that ensures the quality of the final product.

\section{And as specific objectives}

i. Identify the risks of each activity and quantify them.

ii. Analyze the causes associated with identified risks.

iii. Design a plan of recommended action actions for each risk.

\section{Materials and methods}

\section{Design}

It was necessary to clearly define the terms risk and potential failure. The scales of severity, occurrence and detectability. These last three were extracted from the standards QS 9000/ISO TS $16949^{7}$ which, while applicable to the automotive industry, may apply to any process (Tables 1-3). To perform this work, the following procedures were established: admission and registration of blood donors, personal interview, clinical control, donor blood collection, autoexclusion, production of blood components, biological qualification and distribution of blood components. Flowcharts ${ }^{10}$ of each were made as starting points so that all the risks were represented and a matrix was made assigning a number (from 1 and in ascending consecutive order) to the activities that form part of each process (Table 4).

\section{Environment}

The work was done from the chair of Quality in Hemotherapy of the complementary cycle of the Degree in Hemotherapy and Immunohematology. 
Table I Degrees of severity 8,9

\begin{tabular}{|c|c|c|}
\hline Index & Effect & Severity of the effect in the process \\
\hline-10 & $\begin{array}{l}\text { Affects } \\
\text { safety and }\end{array}$ & Risk of survival of human life, community and environment. \\
\hline-9 & legislation & It compromises performance by $75 \%$ and no recovery possible. Damage to any type and level to people. \\
\hline-8 & Critical & $\begin{array}{l}\text { It compromises performance by } 70 \% \text { and no recovery possible. Requires direct management actions. Full customer dissatisfaction } \\
\text { with return/refuse of the product. Serious impact on the process. }\end{array}$ \\
\hline-7 & Important & $\begin{array}{l}\text { Performance impacted up to } 50 \% \text {. Ask for leadership-led actions. Formal customer dissatisfaction in the acquisition of the product. } \\
\text { Impact important in the process or in the delivery of products. }\end{array}$ \\
\hline-6 & & $\begin{array}{l}\text { Impact on performance up to } 25 \% \text {. Ask for shares released by management. Customer dissatisfaction with regular channel claims. } \\
\text { Slight impact on process or delivery of products. }\end{array}$ \\
\hline-5 & 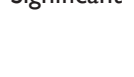 & $\begin{array}{l}\text { Impact on performance up to } 25 \% \text {. Ask for immediate action. There are no complaints or customer dissatisfaction. Slight impact on } \\
\text { the process or delivery of products. }\end{array}$ \\
\hline-4 & Moderate & $\begin{array}{l}\text { Impact on performance of } 10 \% \text {, considering the feasibility of taking actions. Interested parties with complaints if there are } \\
\text { questions. Slight impact on process or delivery of products. }\end{array}$ \\
\hline-3 & Less & $\begin{array}{l}\text { Impact on performance of } 10 \% \text {, considering the feasibility of taking actions. Interested parties do not complain. No impact on the } \\
\text { process or delivery of products. }\end{array}$ \\
\hline-2 & Minimum & Mild inconvenience to the process. No impact on the performance of the indicator \\
\hline-1 & Any & Without perception of the effect on the performance of the process or by the parties interested \\
\hline
\end{tabular}

Table 2 Degree of occurrence ${ }^{8,9}$

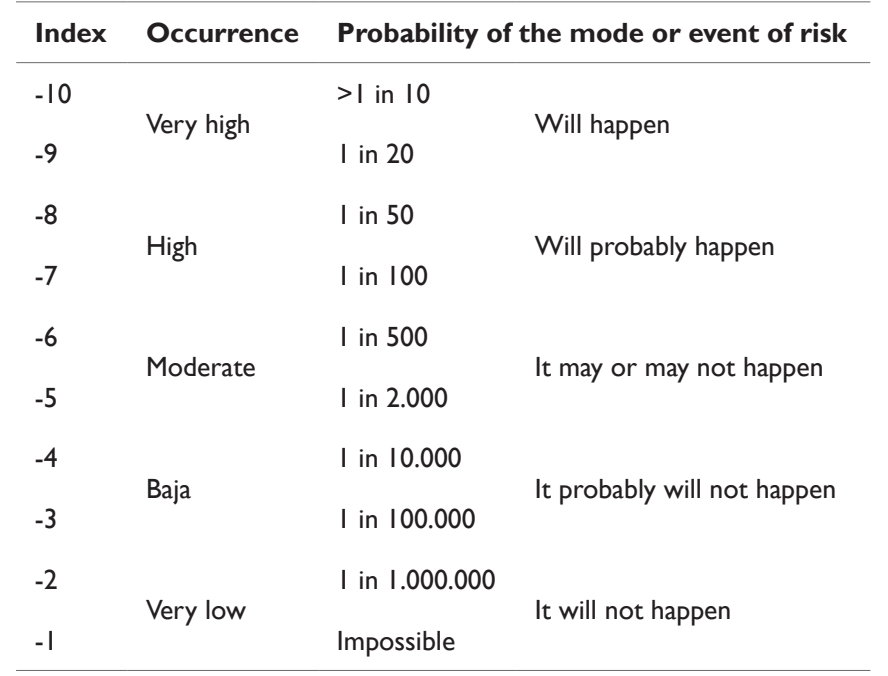

Table 4 Matrix to prepare the AMFE

Analysis of modes of potential failures and their effects (AMFE)

Process:

Product:

Date/Revision:

Involved areas:

Number of activities:

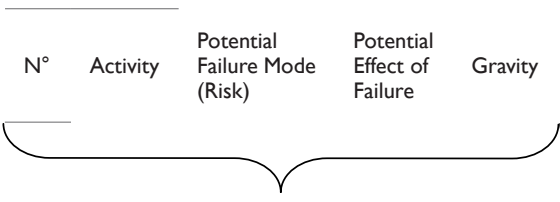

1-Identification

\section{Interventions}

The matrices corresponding to each process mentioned with the
Table 3 Degree of detection ${ }^{8,9}$

\begin{tabular}{lll}
\hline Index & Detection & Probability of detection \\
\hline-10 & Almost impossible & $\begin{array}{l}\text { There is no viable detection method } \\
\text { There is no way to detect with reaction } \\
\text { time }\end{array}$ \\
-8 & Very remote & Detection method is not reliable \\
-7 & Very low & Detection method is not effective \\
-6 & Low & Detection method with low efficacy \\
-5 & Moderate & $\begin{array}{l}\text { Method of detection with average } \\
\text { effectiveness }\end{array}$ \\
-4 & high & Detection method with high efficiency \\
-3 & Very high & $\begin{array}{l}\text { Method of detection effective and in time } \\
\text { of reaction }\end{array}$ \\
-2 & Almost guaranteed & Automatic detection and maybe in time \\
-1 & Guaranteed & Automatic detection and reaction time
\end{tabular}

Staff Involved

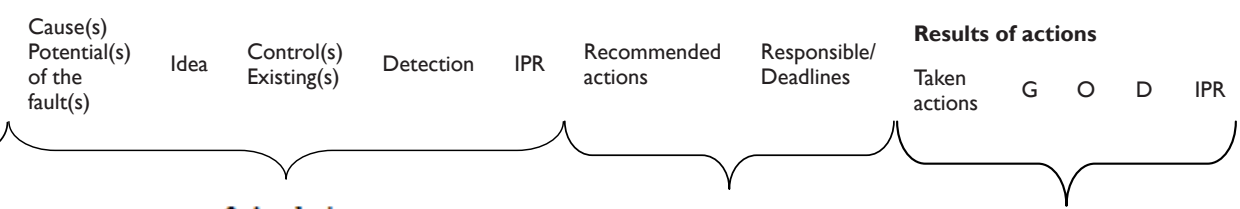

3-Treatment

4-Monitoring

activities in the same order as in the flow charts (PAHO, 2005) were completed, each activity analyzed 
i. The potential risks presented and what their effects or consequences were for assign them a number that represents the degree of severity or severity ( 1 to $10-10$ being the most severe).

ii. The potential causes of the above mentioned risks were then analyzed to assign a number representing the degree of occurrence of the event (1 to 10-10 being the least occurring).

iii. It was determined what type of controls was routinely performed on that activity to assign a number representing the degree of detectability (1 to 10 being 10 undetectable).

Once these three (3) data were obtained, the Risk Priority Index was calculated by applying the following formula:

$\mathrm{IPR}=$ Gravity $(\mathrm{G}) *$ Occurrence $(\mathrm{O}) *$ detectability $(\mathrm{D})$

Table 5 IPR values greater than 100
IPR values were established by consensus limits for each implementation period

\section{Corrective actions}

Immediate actions: IPR $>100$

Short-term Shares: $70<$ IPR $<100$

Medium-term actions: IPR $<70$

Although in ISO 31000 standards

\section{Results}

From the results obtained, we compare the highest IPRs in Table 5 with those with the lowest IPRs in Table 6, since in both we find the most significant data.

\begin{tabular}{|c|c|c|c|c|c|}
\hline Process & Risks & Severity (G) & Occurrence ( 0 ) & Detection (D) & IPR G*O*D \\
\hline \multirow{4}{*}{$\begin{array}{l}\text { Blood } \\
\text { donation }\end{array}$} & Admission of donor in period window & 9 & 3 & 4 & 108 \\
\hline & Incorrect venipuncture site asepsis & 9 & 6 & 4 & 216 \\
\hline & Donor does not manifest self-exclusion decision & 7 & 6 & 4 & 168 \\
\hline & Donor does not understand self-exclusion & 8 & 3 & 10 & 240 \\
\hline \multirow{2}{*}{$\begin{array}{l}\text { Production } \\
\text { of blood } \\
\text { components }\end{array}$} & System open by poorly closed tubing & 9 & 3 & 4 & 108 \\
\hline & Centrifugal malfunction & 9 & 4 & 3 & 108 \\
\hline \multirow{3}{*}{$\begin{array}{l}\text { Biological } \\
\text { classification } \\
\text { of blood } \\
\text { components }\end{array}$} & Improper operation of the label printer & 8 & 7 & 2 & 112 \\
\hline & Poor label glue & 8 & 4 & 4 & 128 \\
\hline & Equipment malfunction & 9 & 4 & 3 & 108 \\
\hline
\end{tabular}

Table 6 IPR values less than 80

\begin{tabular}{|c|c|c|c|c|c|}
\hline Process & Risks & Severity (G) & Occurrence (O) & Detection (D) & IPR G*O*D \\
\hline \multirow{5}{*}{$\begin{array}{l}\text { Blood } \\
\text { donation }\end{array}$} & Ambient air in the exhaust bag before piping. & 9 & 2 & 2 & 36 \\
\hline & Opening of system by badly closed pipe & 9 & 2 & I & 18 \\
\hline & Blood splatter & 9 & 2 & I & 18 \\
\hline & Adverse reaction & 8 & 8 & I & 64 \\
\hline & Defrosting (Plasma) & 9 & 2 & 2 & 36 \\
\hline \multirow{3}{*}{$\begin{array}{l}\text { Biological } \\
\text { classification } \\
\text { of blood } \\
\text { components }\end{array}$} & Exchange of labels between two blood components & 10 & 3 & 2 & 60 \\
\hline & Discarded blood component error & 8 & 2 & 2 & 32 \\
\hline & Do not discard all the blood components produced & 10 & 2 & 2 & 40 \\
\hline
\end{tabular}

\section{Discussion}

In identifying the risks of each activity and quantifying them, as proposed in the specific objectives can be observed the following situations: In Table 6 the IPR results are lower than 70 even in severity is maximal (10) so they do not require immediate action and is due to the occurrence and detection have low values. This can be an indicator of a activity that is under control and is effective. With these parameters the actions to be taken do not urgently as they could be implemented in the medium term. Table 5 shows high IPRs due to human factor errors and equipment problems, giving a guideline where improvement and prevention actions should be focused.
For both cases, the causes associated with these activities are noncompliance with standard operating procedure manuals, omission of blood donor selection criteria by interviewers, insufficient or unclear explanation of the post-donation self-exclusion process, absence of plan maintenance of critical equipment and acquisition of inputs or services without advice from the quality area of the blood bank. In the case of adverse reactions to the donation one can mention as one of the causes a state of anxiety of the donor originated by several reasons.

With the information relayed in this work and in another instance it would be advisable to carry out a causal analysis using a Pareto 
diagram and an Ishikawa diagram for make a more detailed plan of improvements, but with this data can be designed a preventive control plan based on: planning staff training, checking the compliance with standard operating procedures, modification of preventive maintenance planning of equipment and incorporation into the procurement process of a technical report of products and/or services to be procured. The improvement plan should include the measures to be taken, the implementation deadlines and those responsible for each process. ${ }^{11}$

\section{Conclusion}

The analysis of the work done and the results obtained give an indication of the importance of detecting in time the weak points of each process to carry out an efficient planning. The use of this tool can prevent many serious errors that compromise both the health of the blood bank staff and the patients receiving the transfusions. The implementation and maintenance of a process risk management allows, among other things, a company or in this case a blood bank (Argentine Standard IRAM-ISO 31000): ${ }^{5}$

a) Increase the probability of achieving the proposed objectives.

b) Become aware of the need to identify and address risks.

c) Identify opportunities and threats

d) Incorporate and/or improve controls in each area.

e) Manage resources

This management as the guarantee of its effectiveness requires a great commitment from the management or management of the blood bank, which must be firm and sustained, to ensure that the culture of the organization is aligned with established policies.

\section{Acknowledgements}

None.

\section{Conflict of interest}

The author declares no conflict of interest.

\section{References}

1. Vanucci IO. Apunte de Cátedra Inspección y Ensayos. AMFE de Procesos, Argentina: Universidad Tecnológica Nacional-Facultad Regional Córdoba; 2008.

2. Rezzónico RR. Claves para optimizar la Gestión del Conocimiento en los Ambitos Educativos, Científicos, Profesionales y Empresariales. Córdoba, Spain: Tech-Mind-Ed; 2012.

3. John D Roback, Brenda J Grossman, Teresa Harris, et al. Technical Manual. 17th ed. Montgomery, USA: AABB; 2007.

4. http://dle.rae.es/?id=Lg4DGUB

5. Gestión del riesgo. Principios y guías. Norma ISO 31000, Argentina; 2009. p. 1-23.

6. Sistemas de Gestión de la Calidad-Requisitos. Standard ISO 9001, Switzerland; 2015.

7. Automotive Quality Management System Standard. Particular Requirements for the Application of ISO 9001: 2008 for Automotive Organizations of Parties for Production and Relevant Services. ISO/TS 16949, Switzerland; 2009.

8. Clerici Carolina. Textos académicos y cientificos: Pautas de escritura para principiantes. Concepción del Uruguay, Argentina: Espacio Editorial Institucional UCU; 2016.

9. Andrea Villagrán T, Paul R Harris D. Algunas claves para escribir correctamente un artículo científico. Rev Chil Pediatr. 2009;80(1):70-78.

10. Alcorta N. Introducción a la calidad en hemoterapia. Ensayo, Capital Federal, Argentina; 2017.

11. Curso de Gestión de Calidad para Servicios de Sangre. Diccionario Oficial de la Lengua Española, Spain: Real Academia de la Lengua Española; 2005. p. 1-42. 